\title{
El lugar del filósofo en la ciudad. La figura de Sócrates en los escritos de Diderot
}

\section{The place of the philosopher in the city. The figure of Socrates in the writings of Diderot}

\author{
ADRIÁN RATTO \\ Universidad de Buenos Aires - CONICET
}

RESUMEN

El objetivo de este trabajo es demostrar que el lugar que ocupa la figura de Sócrates en la obra de Diderot es problemático, ambivalente. Ciertas actitudes y escritos de Diderot llevaron a sus coetáneos a trazar un paralelismo entre éste y el filósofo ateniense, sin embargo este artículo revela que el editor de la Encyclopédie se alejó de la figura de Sócrates en diferentes ocasiones. Esto arroja algunas luces, por otra parte, acerca de la posición que Diderot mantuvo en sus trabajos de madurez con respecto a la relación entre el filósofo o el sabio y la sociedad

\section{PALABRAS CLAVE}

DIDEROT, SÓCRATES, VIRTUD, FELICIDAD, LEY

\begin{abstract}
The aim of this paper is to demonstrate the problematic, ambivalent nature of Socrates' image in the work of Diderot. Certain attitudes and writings by Diderot led his contemporaries to draw a parallel between him and the Athenian philosopher, yet this article shows that the editor of Encyclopédie distances himself from Socrates' image on different occasions. This, on the other hand, sheds light on Diderot's views on the relation between the philosopher or the sage and the society in his later works.
\end{abstract}

KEYWORDS

DIDEROT, SOCRATES, VIRTUE, HAPPINESS, LAW

(C) Contrastes. Revista Internacional de Filosofia, vol. XXIII-No2 (2018), pp. 25-40. ISSN: 1136-4076 Departamento de Filosofía, Universidad de Málaga, Facultad de Filosofía y Letras Campus de Teatinos, E-29071 Málaga (España) 


\section{INTRODUCCIÓN}

EL 24 DE JULIO DE 1749, tras la publicación ese mismo año de la Lettre sur les aveugles à l'usage de ceux qui voient, Diderot fue encarcelado en el castillo de Vincennes, a unos pocos kilómetros de París. Durante su reclusión, que duró hasta el 3 de noviembre de ese mismo año, comenzó a traducir Apología de Sócrates y Critón de Platón. Su interés por Sócrates, a quien ya había elogiado un año antes en Les bijoux indiscrets (1748), ${ }^{1}$ y su situación llevaron a sus coetáneos rápidamente a trazar un paralelismo entre ambos o, en todo caso, entre Diderot y una de las imágenes de Sócrates que recorrió el siècle des Lumières, a saber, la del filósofo perseguido por autoridades intolerantes. ${ }^{2}$ En una carta al abate Raynal con fecha del 30 de julio de 1749, Voltaire señalaba que la marquesa Émilie du Châtelet había escrito al director de Vincennes para que hiciera menos penosa en la medida de lo posible la reclusión de «SócratesDiderot» (Voltaire 1880, p. 38).

El propósito de este trabajo es examinar el lugar que ocupa la figura de Sócrates en los escritos de Diderot, con el fin de demostrar que la filiación entre el filósofo griego y el francés es menos simple de lo que aparenta ser. Esto arroja luces, por otra parte, sobre la problemática cuestión del papel del sabio o el filósofo frente a las malas leyes en la obra de Diderot, un tema que atrajo particularmente su atención entre los años 60' y 70'.

La estructura del trabajo es la siguiente: en primer lugar(I), se reconstruyen los motivos que llevaron a Diderot a sentir atracción por la figura de Sócrates y se sacan a la luz una serie de sucesos que parecen haber puesto en entredicho ese acercamiento; luego (II), se analizan las alusiones a Sócrates que Diderot realiza en los trabajos que preparó durante su estancia en Rusia, de los que se desprenden nuevos límites en la filiación entre ambos; finalmente (III), a la luz de lo desarrollado en (II) se evalúa la función que tiene la identificación de Diderot con Séneca, otro hombre de la Antigüedad, en uno de sus últimos trabajos, el Essai sur les règnes de Claude et de Néron, escrito pocos años después de su visita a Rusia.

1 Cf. Diderot 1968, p. 171.

2 Raymond Trousson ha demostrado que las imágenes de Sócrates que recorrieron el siècle des Lumières, las cuales respondían a diferentes intereses, en algunos casos contrapuestos entre sí, no fueron, ni siquiera entre les philosophes, homogéneas (cf. Trousson 1967, p. 28). Para una visión de conjunto acerca de las diferentes interpretaciones y reinterpretaciones de la figura de Sócrates que se sucedieron desde la Antigüedad hasta el siècle des Lumières, véase Ismard 2013; Trapp 2006. 


\section{Diderot en Vincennes: ¿Un Sócrates moderno?}

Cuando el 24 de julio de 1749 Diderot fue encarcelado, luego de ser acusado de llevar una vida desordenada y ser el autor de libros libertinos, peligrosos para la religión y las buenas costumbres, la comparación con la situación vivida por Sócrates no tardó en instalarse en su círculo de amistades. Quizá no resulte vano recordar que en el año 399 a. C. moría Sócrates en Atenas, luego de ser acusado por sus compatriotas de corromper a la juventud y no reconocer a los dioses de la ciudad. Tras la condena, terminó con su vida bebiendo un vaso de cicuta. Sus ideas, poco ortodoxas en el terreno de la moral, la religión y la política, le habían granjeado muchos enemigos. Ya en el 423 a. C. Aristófanes lo presentaba en Las nubes como un charlatán, un sofista y lo acusaba de impiedad.

Diderot mismo, en todo caso, alimentaba esa interpretación al comenzar a traducir en su celda la Apología de Sócrates de Platón. En efecto, Diderot poseía allí, entre otros libros, un pequeño volumen que contenía una serie de obras de Platón, a partir del cual tradujo la totalidad de la Apología y parte de Critón. ${ }^{3}$ ¿Cuál fue el motivo del interés de Diderot por esos trabajos? ¿Por qué fueron esos y no otros los diálogos de Platón seleccionados? Sócrates, el mártir de la verdad, el sabio perseguido, se había convertido en una especie de mito en el siècle des Lumières (cf. Trousson 1967, pp. 11-28); en una situación como la que se encontraba Diderot no debe resultar llamativo que se interesara por esos textos de Platón, donde se reconstruye el juicio a Sócrates y sus últimos días. Como señalan Raymond Trousson y Jean Seznec, traducir al francés la Apología era asimilar su suerte a la de Sócrates (cf. Trousson 1978, pp. 238, 239; Seznec 1957, p. 2). Diderot interpretó su encarcelamiento en 1749 y más tarde las persecuciones que tuvo que soportar durante la edición de la Encyclopédie a la luz del proceso a Sócrates. En una carta a Étienne Maurice Falconet, redactada el 15 de febrero de 1766, se pregunta, luego de transcribir algunas palabras de Sócrates en la Apología (de su propia traducción): «¿No estamos los dos [en alusión a Sócrates y a sí mismo] en Atenas» (Diderot 1985, p. 41). Las figuras de Sócrates y Diderot, de París y Atenas, se confunden.

Por otra parte, en la entrada «SocratiQue, philosophie ou Histoire de la Philosophie de Socrate», que Diderot redactó más tarde para el volumen 15 (Sen - Tch) de la Encyclopédie, reconoció expresamente su admiración por

3 Trousson ha examinado cuidadosamente los méritos y las limitaciones de Diderot como traductor y helenista, véase Trousson 1964, pp. 215-245 y Trousson 1969, pp. 141-326. Diderot leyó una parte de la traducción de Apología a su amigo Jean-Jacques Rousseau en una de sus visitas a Vincennes (Rousseau recorrió varias veces en 1749 el camino desde París a Vincennes, para visitar a su amigo), quien utilizó algunos fragmentos de la misma en su célebre Discours sur les sciences et les arts (1751). La traducción completa del texto realizada por Diderot no se publicó hasta 1969. 
el filósofo ateniense. Allí, repasa la vida y las principales ideas de la filosofía de Sócrates. Señala que el filósofo griego había extraído su sabiduría «de la experiencia cotidiana», una actitud que lo diferenciaba de sus predecesores, quienes se habían "perdido en frías especulaciones» acerca de los astros; se había interesado por la «virtud» y la «felicidad» y se había encargado de sacar a los hombres de «las sombras de la superstición». Un proyecto de esta naturaleza, concluye, «no podía llevarse a cabo sin peligro, entre tantos miserables interesados en mantener a los hombres en el vicio, la ignorancia y los prejuicios» (Diderot y d'Alembert 1765, p. 261). Inmediatamente agrega que el filósofo griego le despierta admiración: «tú [Sócrates] me haces llorar de admiración y regocijo» (p. 262). ${ }^{4}$

La figura de Sócrates es asimilada en esa entrada a la de un philosophe, a un hombre del siècle des Lumières. Sócrates es presentado como un individuo que, como el mismo Diderot en la Lettre sur les aveugles, guió su pensamiento a través de la experiencia, evitando así perderse en vanas especulaciones metafísicas; un hombre que intentó alejar a sus conciudadanos de los prejuicios y la ignorancia y conducirlos hacia el camino de la virtud: «Él los alejaba de los prejuicios, los hacía amar la verdad y les inspiraba el gusto por la virtud», dice Diderot a propósito de la relación entre Sócrates y sus conciudadanos (ibíd.).

Sin embargo, ya en ese artículo Diderot evita identificarse sin más con la figura del filósofo ateniense. Antes de confesar su reconocimiento, su admiración por él, señala: «iAh, Sócrates, nos parecemos tan poco!» (ibíd.). Diderot pensaba, seguramente, en su reclusión en Vincennes. Su actitud en ese momento se había parecido poco a la de Sócrates, pese a las apariencias. En efecto, el 29 de julio de 1749, al ser interrogado por Berryer, teniente general de la policía, el editor de la Encyclopédie negó ser el autor de Les Bijoux indiscrets, la Lettre sur les aveugles y Les pensées philosophiques (1746). Pero esto no es todo. El 10 de agosto escribió una carta a Berryer, apelando a su misericordia para hacer menos penosa su situación y la de su mujer. Finalmente, el 13 de agosto, es decir, tres días después, confesó, a través de una nueva carta a Berryer, ser el autor de los libros, comprometiéndose a no publicar nada en el futuro sin antes someter el escrito al control de las autoridades.

Señor, mis penas han llegado tan lejos como se puede llegar, tengo el cuerpo agotado, el espíritu abatido y el alma penetrada por el dolor (...) Le confieso, entonces, como mi protector, aquello que ni los largos días de prisión ni todas las

4 La admiración por el filósofo ateniense lo llevó incluso a concebir el proyecto de escribir una Mort de Socrate, una tragedia que pusiera de relieve el vínculo entre felicidad y virtud, como explicó a Jacob Vernes en una carta del 9 de enero de 1759. Diderot no logró completar el proyecto y finalmente renunció a él. De todas maneras, realizó un boceto del mismo que se publicó en De la poésie dramatique (1758). 
torturas imaginables me habrían hecho decir ante un juez: que los Pensées, las Bijoux la Lettre sur les aveugles son excesos de mi espíritu. Puedo, en todo caso, asegurarle que fueron los últimos y que son los únicos (Diderot 1955, pp. 88, 89).

La confesión rindió sus frutos: el 21 de agosto Berryer avisó al marqués de Châtelet, alcalde de la prisión, que Diderot tenía permiso para salir del torreón donde estaba encerrado y circular con libertad por el castillo. La confesión, por otra parte, comprometió a Madame de Puisieux, su amante, y a los libreros que le habían encargado la edición de la Encyclopédie. Años más tarde, Diderot tuvo la oportunidad de actuar con más valentía, cuando decidió continuar trabajando en la Encyclopédie, pese a la prohibición que pesaba sobre ella. ${ }^{5}$ En todo caso, durante su encierro en Vincennes, no parece haberse hecho digno del nombre «Sócrates-Diderot» que le había atribuido Voltaire.

El temor que experimentó Diderot durante su encierro en Vincennes impidió que pudiera colocarse a la altura de Sócrates. Sin embargo, los motivos que lo llevaron en su obra a tomar distancia de la figura del filósofo griego o, en todo caso, de la imagen de éste que él había elaborado, no fueron solamente de índole biográfica, como se observará a continuación.

\section{Nuevos Límites en LA FILIACiÓN ENTRE SócrateS y DiDEROT}

Las Mélanges philosophiques, historiques, etcétera, pour Catherine II, redactadas por Diderot para la emperatriz de Rusia, Catalina II, durante su estancia en San Petersburgo entre 1773 y 1774, fueron la ocasión de nuevas alusiones a la figura de Sócrates. El 11 de junio de 1773, Diderot emprendió un viaje a Rusia para visitar a la emperatriz. En 1762, Catalina II, que simpatizaba con las ideas de les philosophes, había ofrecido al filósofo su protección, para que pudiera terminar en Rusia la Encyclopédie, que en ese momento estaba prohibida en Francia (Diderot rechazó la invitación en ese momento) y tres años después, en 1765, había adquirido la biblioteca que éste había puesto en venta para reunir una dote para su hija, Angelique. Diderot se sentía en deuda con la emperatriz y entendió en 1773 que había llegado el momento de realizar un viaje a Rusia para satisfacer el deseo de Catalina II de conocerlo personalmente. Su estancia en San Petersburgo se extendió desde el 8 de octubre de 1773 hasta el 5 de marzo de 1774. Durante ese tiempo compartió largas charlas en privado con la emperatriz acerca de cuestiones económicas, jurídicas, filosóficas, literarias

5 La publicación de la Encyclopédie, como se sabe, sufrió interrupciones, prohibiciones y casos de censura. Diderot, no obstante, se negó a abandonar la empresa o a continuarla en el extranjero, como le sugirió Voltaire. Philipp Blom ha reconstruido con precisión el tortuoso proceso de edición y publicación de la obra (Blom 2010). 
y políticas. Las Mélanges, donde Diderot vuelve a ocuparse de Sócrates, son un resultado de ese viaje y de los encuentros con Catalina II. ${ }^{6}$ Diderot alude allí al filósofo griego en dos ocasiones y en ambos casos se aleja de su figura.

Por una parte, cuestiona la postura de Sócrates a propósito de la religión. En efecto, en el capítulo XXI del texto («Première addition sur la tolérance»), en donde aborda el problema de la tolerancia en materia de religión, se refiere a la divinidad, al poder sobrenatural, como una «bella quimera» en la que, entre otros, «ha creído Sócrates» (Diderot 1995a, p. 268). Inmediatamente, se aleja de todo tipo de credo religioso, incluso del deísmo, al que adhería Voltaire y al que él mismo se había acercado en su juventud: «el deísta ha cortado una docena de cabezas de la hidra, pero la que ha dejado reproducirá todas las otras» ( $\mathrm{p}$. 270). ${ }^{7}$ El materialista Diderot no podía seguir en este terreno al filósofo griego.

Por otra parte, critica a Sócrates en el plano político. En el capítulo XLVII («De la morale des rois»), en donde se ocupa de analizar las normas que deben seguir los monarcas, sostiene que existe en el hombre una «inclinación natural» hacia «la felicidad»y que «el único deber» del individuo es, precisamente, alcanzarla (p. 348). ${ }^{8}$ A partir de allí afirma que «la ley que prescribe a los hombres una cosa contraria a la felicidad es una falsa ley y es imposible que dure». Agrega, no obstante, que «es necesario, sin embargo, adecuarse a ella tanto tiempo como dure» (ibid. Las cursivas son nuestras). Las figuras de Sócrates y Arístipo le permiten ilustrar su posición: «Sócrates diría: "yo no aceptaré esta ley porque es mala"; Arístipo respondería: "sé tanto como tú que esta ley es mala, sin embargo, me adecuaré a ella, puesto que si el sabio desprecia una mala ley, autoriza con su ejemplo a todos los insensatos a despreciar las buenas"» (p. 349). Diderot adopta la misma posición que el hedonista Arístipo, al aconsejar la obediencia a las leyes, aun cuando fueran malas. ${ }^{9}$ Así, toma distancia nuevamente del filósofo ateniense.

6 El escrito se publicó recién en 1899, bajo el título Diderot et Catherine II, editado por Maurice Tourneux. A propósito de la relación entre Diderot y Catalina II, véase Binoche 2000, pp. 143-162.

7 Las críticas al deísmo realizadas por los materialistas ateos de la coterie holbachique, a la que pertenecía el mismo Diderot, provocaron profundas tensiones entre estos y Voltaire, quien pretendía contar con ellos como aliados en la lucha contra las religiones reveladas, véase Mortier 1994, pp. 697-704.

8 Robert Mauzi ha demostrado la importancia del concepto de «felicidad» (bonheur) durante el siècle des Lumières en su célebre trabajo L'idée du bonheur dans la littérature et la pensée française au XVIII siècle (Mauzi 1965).

9 Diderot había llegado a la misma conclusión en un pasaje del Salon que escribió en 1767 para la Correspondance littéraire, philosophique et critique de su amigo Grimm. Allí, en unas líneas dedicadas al artista Joseph Vernet, recurre a las figuras de Arístipo y Sócrates. Arístipo, que parece representar el punto de vista de Diderot, se enfrenta al dilema que plantea la posición extrema adoptada por Sócrates frente a 
Ahora bien, si el hombre está inclinado naturalmente a la búsqueda de la felicidad, ¿por qué debe obedecer leyes que lo hacen desdichado? La respuesta es que la felicidad es sobre todo, según Diderot, un fin colectivo. En el mismo pasaje en el que afirma que la felicidad es el fin natural del hombre, dice que todos los deberes del hombre, tanto con respecto a sí mismo, como con respecto a los otros, remiten a la justicia y que ésta es la única virtud: «no hay más que una virtud, la justicia; un solo deber, ser feliz (...). La justicia encierra todo aquello que el hombre se debe a sí mismo, aquello que debe a los otros hombres, a su patria, a su ciudad, a su familia, a su amante, a sus amigos...» (p. 345). Los conceptos de justicia y felicidad coinciden. De esto se sigue que un individuo no puede ser feliz sin ser virtuoso y no puede ser virtuoso si no es a partir de la relación con los demás individuos, es decir, en medio de la sociedad. No hay lugar para la virtud fuera de la ciudad. Una sociedad con malas leyes (aquellas que se alejan de la «utilidad pública») puede ser reformada, en cambio, la fractura de la sociedad, el aislamiento de los individuos, conduce a un régimen contrario a la naturaleza humana, según Diderot (cf. p. 312). De allí el rechazo de Diderot-Arístipo a la actitud de aquellos que deciden huir de la sociedad y las leyes, incluso cuando esa acción está motivada por intenciones nobles. Los hombres no pueden aislarse de los otros hombres sin poner en riesgo su integridad moral. ${ }^{10}$ No es otro el sentido de las palabras vertidas años antes en Le fils naturel (1757): «el hombre de bien vive en sociedad, sólo el canalla vive en soledad» (Diderot 1875a, pp. 65, 66), una frase que había generado una fuerte polémica entre él y su entonces amigo Jean-Jacques Rousseau, que cuando la leyó se encontraba en Montmorency, alejado por voluntad propia de la corte y los salones de París. ${ }^{11}$

las malas leyes: «¡Oh, Sócrates!, sé tanto como tú que la ley es mala y la vida, por otra parte, no me importa demasiado. Sin embargo, me someteré a la ley, ya que temo que de no hacerlo mi actitud sirva como ejemplo a la multitud insensata y fomente la desobediencia a las buenas leyes. No huiré de las cortes como tú. Sabré vestirme de púrpura y acercarme a los poderosos y quizás, logre la abolición de las malas leyes (...)» (Diderot 2008, p. 297).

10 En este aspecto Diderot parece seguir los aires de su época. Como señala Pierre Naudin, durante el siècle des Lumières la soledad, el alejamiento de la sociedad, deja de ser un ideal, un modelo a seguir, como lo era en el siglo XVII, y se convierte en el triunfo de una naturaleza pervertida, extraviada con respecto a sus fines ( $c f$. Naudin 1995, p. 20). A propósito de la relación entre el individuo y la sociedad en el siècle des Lumières, véase Cussac y Richard-Pauchet 2016, pp. 11-25. También puede consultarse el dossier «Individus et communautés», dirigido por Ives Citton y Laurent Loty 2009.

11 Jean Fabre ha reconstruido los diferentes momentos de la problemática relación entre ambos. Véase Fabre 1961, pp. 155-213. 
La intransigencia de la moral socrática amenaza el orden social mismo, por eso Diderot se inclina por la figura de Arístipo frente a la de Sócrates. ${ }^{12}$ Así, en las Mélanges los ejes de las alusiones a Sócrates se modifican: ya no se trata del filósofo perseguido por las autoridades intolerantes, sino de alguien que con su actitud pone en riesgo el lazo social. En ese marco Diderot sostiene que, si bien el «el filósofo» es, a diferencia de «la masa general de individuos», capaz de distinguir las leyes buenas de las malas ( $c f$. Diderot 1995a, pp. 348, 349), no está autorizado a desobedecerlas en ningún caso. El hombre sabio puede, en todo caso, juzgar en su foro interno esas leyes o trabajar para que se modifiquen en el futuro, pero debe obedecerlas en el presente (cf. p. 348).

Sobre esta base se apoya el propósito general de las Mélanges, que Diderot entregó a la emperatriz antes de dejar Rusia. En el texto se trazan las líneas principales de un plan de reforma del imperio, de un programa que tenía como fin convertir a Rusia en una nación próspera, ilustrada y floreciente. No se trataba de subvertir el orden político ruso o de rechazar completamente el estado de cosas existente, sino de trabajar junto a la emperatriz en la modificación de algunos aspectos de la política rusa. Diderot consideraba a Catalina II una déspota, como escribió en sus Observations sur le Nakaz en 1774, durante su viaje de regreso a Francia tras la estancia en Rusia [«La emperatriz de Rusia es ciertamente una déspota» (Diderot 1995b, p. 508) ${ }^{13}$ ], sin embargo, no pretendía derribar su régimen despótico o alejarse rápidamente del mismo, sino trabajar para modificarlo.

Los aspectos más destacados de ese programa para reformar Rusia, que Diderot desarrolla en las Mélanges, son: el fomento del comercio y los oficios (caps. LVII y LVIII); la creación de una comisión permanente que sea capaz de controlar las leyes y contrabalancear el poder del soberano (cap. XXIV); la creación de institutos de educación pública, que reemplacen los privilegios por el mérito (cap. XXV) [un tema que también abordó en otro escrito de la misma época, que envió a Catalina II en 1775 y que sirve como complemento de las Mélanges en este punto, el Plan d'une Université pour le gouvernement de Russie (publicación póstuma en 1813)] y la modernización del estado (cap. XXVI).

El final del Supplément au voyage de Bougainville, un cuento filosófico redactado en 1772 (publicación póstuma en 1796), es decir un año antes del viaje de Diderot a Rusia, anticipa e ilustra la postura que un año más tarde

12 La interpretación de Diderot parece, no obstante, un tanto forzada, ya que Sócrates llegó a beber la cicuta para cumplir la condena que, precisamente, le habían impuesto los tribunales de su ciudad.

13 La emperatriz leyó las Observations sur le Nakaz luego de la muerte de Diderot y ordenó destruirlas. 
adoptaría en las Mélanges. El libro se apoya en las experiencias de viaje relatadas por Louis-Antoine de Bougainville en su Voyage autour du monde (1771) y gira en torno a la cuestión de los usos y las costumbres en tierras no europeas. A través de un relato ficticio Diderot compara las costumbres de los salvajes tahitianos con las de los europeos. ${ }^{14}$ Al final del Supplément uno de los personajes, $A$, le pregunta a otro, $B$ : «dígame, ¿hay que civilizar al hombre o dejar que viva según sus instintos?» (Diderot 1875b, p. 246); y un poco después repite la pregunta: «¿Qué haremos, entonces? ¿Nos someteremos a las leyes? ¿Volveremos a la naturaleza?». $B$ responde, anticipando la posición que Diderot tomaría explícitamente un año después: «criticaremos las leyes insensatas hasta que sean reformadas, pero, hasta que eso suceda, nos someteremos a ellas (...) ser un loco entre los locos es menos problemático que ser un sabio en soledad» (p. 249).

\section{EL SABIO COMPROMETIDO CON LA POLÍTICA}

En 1777, tres años después de la redacción de las Mélanges, Diderot se comprometió a escribir un trabajo sobre la vida y la obra de Séneca. El editor de la Encyclopédie encontró en este otro gran personaje de la Antigüedad algo que no le ofrecía la figura de Sócrates. ${ }^{15}$

Jacques-André Naigeon y el barón d'Holbach encargaron a Diderot en 1777 una vida de Séneca para coronar la traducción al francés de los trabajos del filósofo romano realizada por M. de La Grange y el mismo Naigeon. La obra se publicó en diciembre de 1778, bajo el título de Essai sur Sénèque le philosophe, sur ses écrits et sur les règnes de Claude et de Néron, y se reeditó en 1782 con agregados y las respuestas a las críticas a la primera edición vertidas principalmente en l'Année littéraire y el Journal de Paris, con el nombre Essai sur les règnes de Claude et de Néron, et sur les mœurs et les écrits de Sénèque, pour servir d'introduction à la lecture de ce philosophe. El trabajo parece a primera vista un frío tratado erudito enmarcado en la tradición clá-

14 El análisis de las costumbres europeas a la luz de las costumbres de sociedades extranjeras fue un tema de moda en el siècle des Lumières, una cuestión abordada, por ejemplo, en las Lettres persannes (1721) de Montesquieu o Candide (1759) de Voltaire, por mencionar sólo algunas obras. María José Villaverde y Gerardo López Sastre han reunido recientemente una serie de trabajos a propósito de la mirada de los ilustrados con respecto al mundo no europeo, véase Villaverde y López Sastre 2015.

15 Con respecto a la recepción de la figura y los escritos de Séneca en el siglo XVIII, véase Conroy 1975 (en particular el capítulo: «The tradition of Seneca's studies», pp. 25-33). Para una visión de conjunto acerca de la recepción de la Antigüedad en el siècle des Lumières, véase Grell 1995. Acerca de la relación de Diderot en particular con la Antigüedad, véase Seznec 1957 (llamativamente Seznec no dedica ningún capítulo a la relación de Diderot con los trabajos de Séneca). 
sica. El libro está dividido en dos partes, la primera, que sigue de cerca los relatos de los historiadores romanos Tácito y Suetonio vertidos en Annales y en De vita Caesarum respectivamente, está consagrada a la vida de Séneca; la segunda, al análisis de sus obras. Las palabras que el mismo Diderot desliza en la dedicatoria a Naigeon, las cuales encabezan la segunda edición de la obra, parecen alimentar esta interpretación: «se trata [dice Diderot] de examinar sin parcialidad la vida y las obras de Séneca» (Diderot 1986, p. 35). Sin embargo, este escrito se encuentra lejos de ser un mero trabajo académico. El Essai es un libro complejo en el que se mezclan las voces de Diderot y de Séneca, las discusiones de la época de Nerón (I d. C.) y las del siglo XVIII francés, las críticas a La Mettrie y la polémica entre el filósofo y su amigo de antaño Jean-Jacques Rousseau, entre otras cosas.

En efecto, a pesar de las apariencias, el Essai no es una mera presentación imparcial de la figura de Séneca, sino una defensa de la vida y la obra del autor de De tranquillitate animi. El escrito de Diderot fue mucho más allá del pedido que había recibido. Luego de afirmar que el hombre firme y honesto «conserva su puesto, aunque ve aproximarse su pérdida», dice que Séneca actuó correctamente al permanecer al lado de Nerón pese a la aversión que éste le causaba ( $\mathrm{p}$. 91). Abandonar a Nerón, librarlo a sus perversos deseos, hubiera representado, agrega Diderot, «una falta grave» (p. 92). ${ }^{16} \mathrm{Al}$ conservar su puesto, explica, el filósofo romano veló por el bienestar de sus amigos, familiares y de los ciudadanos en general. «Cuanto más desordenado, ignorante, disoluto y feroz es el príncipe, más valioso es el papel del sabio comprometido», desliza poco después (ibíd.). Elogia, de esta manera, al sabio que se implica en los asuntos de la ciudad, a aquel que es capaz de luchar para modificar o, en todo caso, moderar las extraviadas decisiones de los malos príncipes (cf. pp. 93, 94).

Estas reflexiones de Diderot se apoyan, como en las Mélanges, sobre los conceptos de «virtud»y «felicidad». De la misma manera que en ese trabajo, en el Essai sostiene, luego de afirmar que «no hay felicidad sin virtud», que «no hay más que un deber, ser feliz, y no hay más que una virtud, la justicia» (p. 344). De esto se sigue, como en las Mélanges, que el hombre no puede llegar a ser feliz sin atender a la relación con los otros individuos, es decir, a las leyes, a la política, a la utilidad pública. En otras palabras, no es posible alcanzar la felicidad y la virtud fuera de la sociedad. Por esta razón toma distancia de aquellos que advirtiendo los problemas de la sociedad en la que viven optan por alejarse de ella, aquellos que se evaden de la comunidad, que se refugian en los bosques o en la interioridad: «Amo al sabio en acción como al atleta sobre la arena: el hombre fuerte solo se reconoce cuando existe una ocasión de

16 Llega a la misma conclusión cuando evalúa la manera de actuar de Séneca después de la muerte del virtuoso Burro ( $c f$. Diderot 1986, p. 141). 
demostrar su fortaleza» (p. 251). Estas son las razones que lo llevan a confesar su admiración por Séneca y a lamentar no haberse acercado antes a su filosofía: «¡Ah, si hubiera leído antes las obras de Séneca, si hubiera adoptado sus principios a la edad de treinta años (...)!» (p. 398).

Diderot se retracta en ese trabajo de las palabras vertidas en 1745 en el Essai sur le mérite et la vertu, un trabajo de juventud, en el que en una nota al pie de página había criticado a Séneca acusándolo por su papel junto a Nerón. Allí, Diderot presenta a Nerón atormentado por los terribles actos cometidos y cuestiona el «vergonzoso silencio» de Séneca frente a los mismos, así como su preocupación por «aumentar su riqueza» antes que por enseñar a su pupilo a actuar de una manera acorde a la virtud (Diderot 1875c, p. 118). «Se pensará que trato a este filósofo [Séneca] de una manera un poco dura, pero no es posible, a partir del relato de Tácito [Anales], pensar de otra manera», dice Diderot al final de la nota. En el Essai sur les règnes de Claude et de Néron cambia de posición con respecto a la figura del filósofo romano: «un joven autor que estimo y a quien puedo dirigirme sin rodeos, ha publicado la crítica más lacónica y violenta que se haya hecho a Séneca (...)». Así, luego de reproducir algunos pasajes de la nota al pie de página escrita por él mismo en el trabajo de 1745 , exclama: «¿De dónde has tomado todo esto? ¿Sobre qué apoyas tus críticas? (...). Cuando sientas en el propio cuerpo la lucha del sabio, te sentirás turbado por las injurias que has lanzado contra el más virtuoso y, yo agregaría, el más desdichado de los hombres, si es que se puede ligar la virtud a la desdicha» (Diderot, 1986, p. 204).

Séneca ofreció a Diderot en 1777 la imagen de un filósofo comprometido, un hombre capaz de conjugar su sabiduría con su rol de ciudadano, un ideal al que ya no parecía responder la inflexible figura de Sócrates. Franco Venturi señala que Diderot se «esconde detrás de las costumbres y la máscara de Séneca» (Venturi 1992, p. 15) y Jean Deprún no duda en afirmar que en ese trabajo la voz de Séneca es al mismo tiempo la voz de Diderot (cf. Deprún 1986, pp. 25, 26). Es verdad que Diderot no evita hacer algunas críticas a la obra de Seneca, como se puede advertir, por ejemplo, en $\S 8$ de la segunda parte del escrito donde examina una de las cartas de Séneca a Lucilio, en la que el filósofo romano le aconseja exhortar a su amigo a permanecer en el retiro. Diderot reacciona ante la posición adoptada allí por Séneca ( $c f$. Diderot 1986, p. 251). Sin embargo, esas críticas a algunos pasajes aislados de su obra no impiden que declare su admiración por Séneca y lo tome como un modelo por el papel que desarrolló al lado de Nerón ( $c f$. p. 123).

\section{CONCLusión}

Russell Goulbourne afirma que desde el encarcelamiento en Vincennes la figura de Sócrates se convierte en una «imagen especular» de Diderot (Goul- 
bourne 2011, p. 21) y Nicholas Furbank señala que a partir de la traducción de la Apología Diderot se «auto-identifica» con el filósofo griego (Furbank 1992, p. 53). Asimismo, Raymond Trousson sostiene que el editor de la Encyclopédie «aspiró toda su vida a cubrirse con el manto de Sócrates» (Trousson 1967, pp. 59, 60) y Sophie Bourgault, que la atracción de Diderot «por el hijo de Sofronisco fue inquebrantable» (Bourgault 2010, p. 47). A partir de lo desarrollado en este escrito, se puede afirmar que estas interpretaciones corren el riesgo de simplificar la relación que se puede establecer entre las figuras de Diderot y Sócrates. Se desprende de este trabajo que la filiación entre ambos es problemática, ambivalente. En efecto, si bien es necesario reconocer la admiración que por momentos Diderot expresa por el filósofo ateniense y su expresa intención en algunos casos de hacer coincidir sus figuras, se debe señalar también que el editor de la Encyclopédie se distancia en diferentes aspectos de Sócrates. En primer lugar, como se ha demostrado en (I), Diderot toma distancia de la figura de Sócrates por motivos biográficos, a saber, su vergonzoso comportamiento durante su encierro en Vincennes. En segundo lugar, se aleja del filósofo ateniense por motivos metafísicos y religiosos: Sócrates a diferencia del materialista Diderot no rechaza la existencia de algún tipo de divinidad. Finalmente, el filósofo francés no acepta en las Mélanges la rígida e intransigente moral socrática, en la medida en que la misma, entiende, puede poner en riesgo el orden social al que los hombres están naturalmente inclinados. Esto último lo acerca en sus últimos escritos a la figura de Séneca, como se puede observar en (III), en quien encuentra un sabio comprometido con los asuntos públicos, un filósofo que se mantiene al lado del tirano con el fin de proteger a sus familiares, amigos y conciudadanos, un individuo que coloca la utilidad pública por encima de su interés particular. Se podría, tal vez, agregar un cuarto motivo de tensión entre los personajes, a saber, la distancia entre el Sócrates imaginado por Diderot y el Sócrates histórico que empezaba a conocerse en la época a través de trabajos de filólogos y eruditos como Nicolas Fréret, quien en sus Observations sur les causes et sur quelques circonstances de la condamnation de Socrate (1736), concluía, luego de un examen cuidadoso de las fuentes vinculadas al tema, que el Sócrates histórico no estaba a la altura del mito en torno al personaje, que se había elaborado en la época (cf. Freret 1981, p. 107). ${ }^{17}$

Por otra parte, el análisis de la figura de Sócrates en las Mélanges pone de relieve algunos aspectos de la posición política de Diderot durante esos años. El sabio o el filósofo, dice Diderot, no debe desobedecer las normas, ni siquiera en aquellas sociedades donde rigen malas leyes. En todo caso, puede trabajar

17 Mario Montuori se ha ocupado de analizar detalladamente la distancia entre el Sócrates histórico y la imagen que recorrió el siglo XVIII, véase Montuori 1981. 
para modificarlas en el futuro. Ése es el papel que el mismo Diderot jugó junto a Catalina II, a la que consideraba una déspota; ésa es la base sobre la que se apoya su plan de reformas para Rusia. No se trata de alejarse y colocarse en un lugar desde el cual poder decir la verdad, como buscaba Rousseau en los años 50' al rechazar una pensión real y abandonar París para refugiarse en la soledad de Montmorency, ante la mirada atónica de Diderot y el resto de la coterie holbachique, sino de trabajar para reformar efectivamente la sociedad. «No huiré de las cortes como tú. Sabré vestirme de púrpura y acercarme a los poderosos y quizás, logre la abolición de las malas leyes (...)», decía Arístipo a Sócrates en un diálogo ficticio redactado por Diderot pocos años antes de las Mélanges. ${ }^{18}$

Finalmente, el trabajo arroja algunas luces sobre el papel de Diderot como historiador, un tema que, si se excluyen algunos trabajos aislados (Brot 2010, pp. 61-80; Mall 2006, pp. 127-136), no ha logrado atraer aún el interés de los especialistas. Se puede advertir en el trabajo que las figuras de Sócrates y Séneca se mezclan con los problemas del siglo XVIII, Roma y Atenas se confunden con París, Diderot no parece distinguir el pasado del presente. El filósofo parece mantener el lugar tradicional de la historia como un terreno instrumental a la política, frente a quienes en su época intentaban modificar, a la luz del desarrollo científico, los métodos historiográficos, para hacer de la historia una disciplina independiente. ${ }^{19}$ Este último tema, en todo caso, desborda los límites de este escrito.

\section{REFERENCIAS BIBLIOGRÁFICAS}

BINOCHE, B. 2000: «Diderot et Catherine II», en B. Binoche y F. Tinland eds., Sens du devenir et pensée de l'histoire au temps des lumières. Seyssel: Champ Vallon, pp. 143-162.

BLOM, P. 2010: Encyclopédie. El triunfo de la razón en tiempos irracionales (trad. Javier Calzada). Barcelona: Anagrama.

BOURGAULT, S. 2010: «Appeals to Antiquity: Reflections on some French Enlightenment Readings of Socrates and Plato», Lumen, vol. 29, pp. 43-58.

BROT, M. 2010: «Diderot historien juge de lui-même dans l'Essai sur les règnes de Claude et de Néron», en M. Leca-Tsiomis y A. Sandrier eds., Diderot, l'Encyclopédie et autres études. Sillages de Jacques Proust. Ferney: Centre international d'étude du XVIII ${ }^{\mathrm{e}}$ siècle, pp. 61-80.

CITTON, I. y LOTY, L. dir. 2009: «Individus et communautés», Dix-huitième siècle, vol. 41.

18 Supra nota 9.

19 A propósito de las modificaciones que se producen en el terreno del saber histórico en el siglo XVIII, véase Pommian 1975. Véase también Grell 1993. 
CONROY, W. 1975: Diderot's Essai sur Sénèque. Voltaire Foundation: Oxford.

CUSSAC, H. y RICHARD-PAUCHET, O. 2016: «La retraite au 18e siècle: désir ou chimère?», Dix-huitième siècle, vol. 48, pp. 11-25.

DEPRUN, J. 1986: «Diderot au travail. Introduction à l'Essai sur les règnes de Claude et de Néron», en D. Diderot, Euvres complètes (ed. Jean Fabre, Herbert Dieckmann, Jacques Proust y Jean Varloot). París: Hermann, vol. 25, pp. 19-26.

DIDEROT, D y D'ALEMBERT, J. eds. 1765: Encyclopédie ou Dictionnaire raisonné des sciences, des arts et des métiers par une société des gens de lettres. París: Briasson - David - Le Breton - Durand, vol. 15, pp. 261-265.

DIDEROT, D. 1875a: Le fils naturel, en D. Diderot, Euvres complètes (ed. Jules Assézat y Maurice Tourneux). París: Garnier Frères, vol. 7.

___ 1875b: Supplément au voyage de Bougainville, en D. Diderot, Euvres complètes. París: Garnier Frères, vol. 2.

___ 1875c : Essai sur le mérite et la vertu, en D. Diderot, Euvres complètes. París: Garnier Frères, vol. 1.

___ 1955: Correspondance (ed. Georges Roth y Jean Varloot). París: Éditions de Minuit .

___ 1968: Les Bijoux indiscrets (prefacio de Antoine Adam). Garnier-Flammarion, París.

1985: Le pour et le contre, ou lettres sur la postérité, en D. Diderot, Euvres complètes (ed. Jean Fabre, Herbert Dieckmann, Jacques Proust y Jean Varloot). París: Hermann, vol. 15.

1986: Essai sur les règnes de Claude et de Néron, en D. Diderot, Euvres complètes. París: Hermann, vol. 25.

___ 1995a: Mélanges philosophiques, historiques, etcétera, pour Catherine II, en D. Diderot, Euvres (ed. Laurent Versini). París: Robert Lafont, vol. 3.

___ 1995b: Observations sur le Nakaz, en D. Diderot, Euvres. París: Robert Lafont, vol. 3.

___ 2008: Salon de 1767, en D. Diderot, Salons (ed. Michel Delon). París: Gallimard.

FABRE, J. 1961: «Deux frères enemies: Diderot et Jean-Jacques», Diderot Studies, vol. 3, pp. 155-213.

FRERET, N. 1981: Observations sur les causes et sur quelques circonstances de la condamnation de Socrate, en M. Montuori comp., De Socrate iuste damnato: la nascita del problema socratico nel XVIII secolo. Roma: Edizioni Dell'ateneo.

FURBANK, N. 1992: Diderot: A Critical Biography. London: Minerva.

GOULBOURNE, R. 2011: «Diderot and the Ancients», en J. Fowler ed., New Essays on Diderot. Cambridge: Cambridge University Press, pp. 13-30.

GRELL, C. 1993: L'histoire entre érudition et philosophie: étude sur la connaissance historique à l'âge des Lumières. París: Presses universitaires de France. 
1995: Le dix-huitième siècle et l'antiquité en France, 1680-1789. Voltaire Foundation: Oxford.

ISMARD, P. 2013: L'évènement Socrate. París: Flammarion.

MALL, L. 2006 «Diderot historien ou l'art du clair-obscur», en M.-A. Bernier ed., Parallèle des Anciens et des Modernes. Rhétorique, histoire et esthétique au siècle des Lumières. Québec: Presses de l’Université Laval, pp. 127-136.

MAUZI, R. 1965: L'idée du bonheur dans la littérature et la pensée française au XVIII siècle. París: Armand Colin.

MONTUORI, M. 1981: Socrates, Physiology of a Myth (trad. M. Langdale). Amsterdam: J. C. Gieben.

MORTIER, R. 1994: «Ce maudit Système de la nature», en U. Kölvig y C. Mervaud eds., Voltaire et ses combats. Oxford: Voltaire Foundation, pp. 697-704.

NAUDIN, P. 1995: L'expérience et le sentiment de la solitude, de l'aube des Lumières à la Révolution. París: Klincksieck.

POMIAN, K. 1975: «L'histoire de la science et l'histoire de l'histoire», Annales. Économies, Sociétés, Civilisations, vol. 5, pp. 935-952.

SEZNEC, J. 1957: Essais sur Diderot et l'Antiquité. Oxford: Clarendon Press.

TRAPP, M. ed. 2006: Socrates, from Antiquity to the Enlightenment. Hampshire: Ashgate.

TROUSSON, R. 1964: «Diderot et l'antiquité grecque», Diderot Studies, vol. 6, pp. $215-245$.

___ 1967: Socrate devant Voltaire, Diderot, Rousseau. París: Minard.

, 1969: «Diderot helleniste», Diderot Studies, vol. 12, pp. 141-326.

, 1978: «Introduction à la traduction de l'Apologie de Socrate de Platon par Diderot», en D. Diderot, Euvres complètes (ed. Jean Fabre, Herbert Dieckmann, Jacques Proust y Jean Varloot). París: Hermann, vol. 4.

VENTURI, F. 1992: «La vieillesse de Diderot», Recherches sur Diderot et sur l'Encyclopédie, vol. 13, n 1, pp. 9-30.

VILLAVERDE, M. y LÓPEZ SASTRE, G. eds. 2015: Civilizados y salvajes. La mirada de los ilustrados sobre el mundo no europeo. Madrid: Centro de Estudios Políticos y Constitucionales.

VOLTAIRE 1880: Correspondance, en Voltaire, CEuvres complètes (ed. Louis Moland). París: Garnier, vol. 37.

Adrián Ratto es Doctor en Filosofía por la Universidad de Buenos Aires. Actualmente se desempeña como investigador asistente en el Consejo Nacional de Investigaciones Científicas y Técnicas (CONICET) y como docente en la Facultad de Filosofía y Letras de la Universidad de Buenos Aires. Es miembro de la Asociación Argentina de Estudios del Siglo XVIII (AADES XVIII) y de la Société française d'étude du dix-huitième siècle (SFEDS). 
Lineas de investigación

Filosofía francesa del siglo XVIII

Dirección postal:

Av. Luis María Campos 381, $3^{\circ}$ “A”, Ciudad Autónoma de Buenos Aires, Argentina. CP: 1426.

E-mail:ga_ratto@yahoo.com.ar 